\title{
PAPER
}

\section{Changes in gait and fatigue from morning to afternoon in people with multiple sclerosis}

\author{
M E Morris, C Cantwell, L Vowels, K Dodd
}

J Neurol Neurosurg Psychiatry 2002;72:361-365

See end of article for authors' affiliations ......................

Correspondence to: Professor M Morris, School of Physiotherapy, La Trobe University, 3086, Australia m.morris@latrobe.edu.au

Received

21 February 2001

In revised form

12 November 2001

Accepted

14 November 2001

\begin{abstract}
Objectives: The aim was to measure changes in walking patterns and self rated fatigue in people with multiple sclerosis (MS) compared with age matched control subjects, from the morning to the afternoon within a single day.

Methods: Fourteen patients with MS and the same number of matched control subjects performed four $10 \mathrm{~m}$ gait trials at their preferred walking speed at $1000 \mathrm{am}$ and then again at $300 \mathrm{pm}$ on the same day. Gait speed, stride length, cadence, and the percentage of the gait cycle spent in double limb support were measured using a foot switch stride analyzer. Patients with MS also self rated their fatigue levels in the morning and afternoon using an 11 point scale.

Results: Compared with control subjects, patients walked very slowly, with reduced stride length and around twice as much variability in gait performance. Although self rated fatigue significantly increased from the morning to the afternoon, walking patterns remained consistent in both groups over the course of the day.

Conclusions: These findings imply that mechanisms controlling locomotion are separate from those regulating perceived fatigue. Objective measures of performance, rather than self report, should be used to monitor change in patients with multiple sclerosis.
\end{abstract}

M ultiple sclerosis (MS) is a progressive neurological disorder, characterised by exacerbations and remissions, affecting movement, cognition, and perception. ${ }^{1}$ Due to demyelination, ${ }^{2}{ }^{3}$ axonal damage, ${ }^{3}$ and the formation of sclerotic plaques in the cerebral hemispheres, ${ }^{2}$ brain stem ${ }^{4}$ and spinal cord, ${ }^{56}$ movement disorders and gait disturbance are common in patients with MS. Nerve conduction alters with the variations in sclerosis and inflammation and therefore symptoms change over time. ${ }^{7}$ The degree of variability in movement performance differs between patients ${ }^{3}$ and changes at different rates over periods of months to years. ${ }^{89}$ At times there can be a plateau in motor performance $^{10}$ or slight improvements due to reduction of inflammation, ${ }^{7}$ whereas at other times there is sudden deterioration due to rapid demyelination for reasons that are not completely understood. ${ }^{7112}$

Gait disturbance and fatigue are two of the most frequent and disabling sequelae of MS. Eighty five per cent of patients report gait disturbance as their main complaint. ${ }^{13}$ Moreover only two thirds retain the ability to walk 20 years after diagnosis. ${ }^{14}$ Due to disorders such as spasticity, incoordination, weakness, and vestibular disturbance, patients typically walk slowly with a shorter stride length and more prolonged double support phase..$^{15-20}$ They can also require rests due to fatigue. ${ }^{21}$ There is some evidence that fatigue correlates more highly with depression, ${ }^{22-24}$ cognitive impairment, ${ }^{23}{ }^{25}$ social functioning, and feelings of wellbeing than physical performance. ${ }^{23}$ The degree to which fatigue in MS correlates with disorders of locomotion has not previously been investigated.

For neurologists, physical therapists, and nurses to make clinical decisions about rate of disease progression and effectiveness of treatment in MS, they need to have information on the consistency of performance in the absence of intervention. Although some large clinical trials have charted the time course of disease progression over months and years, ${ }^{9}{ }^{1026} 27$ there have only been a handful of studies evaluating change in gait indices over time, and these have been restricted to analyses of reliability over the course of a day. ${ }^{19}{ }^{28-30}$

In one such study, Holden et al ${ }^{28}$ documented the repeatability of spatial and temporal indices of the footstep pattern in 24 patients with MS compared with 37 hemiplegic patients. They found high retest reliability for repeat measures of performance spaced 15 minutes apart in patients with MS ( $r=0.92-$ 0.98). The findings of Holden et al are limited as the subphases of the gait cycle, such as single limb and double limb support phases, were not quantified and the protocol did not control for the use of assistive devices such as sticks or walking frames. The consistency of gait performance from morning to afternoon, when the effects of fatigue might be more apparent, was not measured.

Vaney et $a l^{30}$ also charted changes in gait over time by measuring walking speed over $10 \mathrm{~m}$ in 25 patients with MS on five different occasions within a single day. Measurements were taken at hourly intervals. Group mean variability of walking speed proved to be relatively high over the day. In a similar way, Gehlsen et al ${ }^{16}$ assessed walking patterns of nine patients with MS on three occasions over a 10 week period. Analysis of two dimensional motion analysis data collected from a videocamera system showed that patients with MS had shorter stride lengths, slower self selected walking speeds, and higher cadence than unimpaired people. However, there were no significant changes in gait variables over the 10 week period in response to interventions delivered during that time.

Thus although research has reported the repeatability of gait in patients with MS over a 15 minute and a 1 hour period, repeatability over a 5 hour period is yet to be investigated. This is the time interval over which gait interventions such as physical therapy and adductor nerve blocks provided on a single day are usually evaluated. Given the paucity of data on gait performance in patients with MS, the purposes of the current study were to: (1) compare the temporal and spatial parameters of gait in patients with MS with age, sex, and height matched control subjects; (2) measure gait consistency from morning to afternoon in patients compared with control

Abbreviations: MS, multiple sclerosis; EDSS, expanded disability status scale 


\begin{tabular}{|c|c|c|c|c|c|c|c|c|c|c|c|}
\hline \multirow[b]{2}{*}{ Patient } & \multirow[b]{2}{*}{ Sex } & \multirow[b]{2}{*}{ Age (y) } & \multirow{2}{*}{$\begin{array}{l}\text { Height } \\
\text { (m) }\end{array}$} & \multirow{2}{*}{$\begin{array}{l}\text { Weight } \\
(\mathrm{kg})\end{array}$} & \multicolumn{2}{|c|}{ Leg length $(\mathrm{m})$} & \multicolumn{2}{|c|}{ Fatigue rating } & \multirow[b]{2}{*}{ EDSS } & \multirow{2}{*}{$\begin{array}{l}\text { Duration } \\
\text { of MS } \\
\text { (y) }\end{array}$} & \multirow{2}{*}{ Medication } \\
\hline & & & & & Left & Right & am & $\mathrm{pm}$ & & & \\
\hline 1 & $\mathrm{~F}$ & 27 & 1.57 & 61.8 & 0.73 & 0.73 & 0 & 0 & 3.5 & 7 & $\mathrm{Nil}$ \\
\hline 2 & $\mathrm{~F}$ & 55 & 1.69 & 57.5 & 0.81 & 0.81 & 0 & 0 & 5.5 & 8 & Betaferon \\
\hline 3 & $\mathrm{~F}$ & 49 & 1.65 & 72.2 & 0.78 & 0.78 & 6 & 6 & 3.5 & 9 & $\mathrm{Nil}$ \\
\hline 4 & $M$ & 36 & 1.81 & 90.8 & 0.87 & 0.87 & 6 & 5.5 & 3.5 & 6 & Betaferon \\
\hline 5 & $M$ & 52 & 1.69 & 83.4 & 0.81 & 0.81 & 0 & 1 & 4.5 & 17 & Betaferon \\
\hline 6 & $M$ & 26 & 1.89 & 78.2 & 0.88 & 0.88 & 4.5 & 6 & 2.5 & 1 & Betaferon \\
\hline 7 & $M$ & 34 & 1.69 & 74.2 & 0.73 & 0.75 & 3 & 5 & 4.5 & 15 & Tegretol \\
\hline 8 & $M$ & 46 & 1.78 & 75.6 & 0.91 & 0.91 & 5 & 8 & 4.5 & 1 & Betaferon \\
\hline 9 & $M$ & 42 & 1.79 & 72.6 & 0.88 & 0.87 & 0 & 3 & 4.5 & 4 & Cortisone \\
\hline 10 & $\mathrm{~F}$ & 32 & 1.61 & 57.0 & 0.84 & 0.83 & 2 & 2 & 3.0 & 4 & Betaferon \\
\hline 11 & $\mathrm{~F}$ & 37 & 1.72 & 63.7 & 0.84 & 0.84 & 3 & 4 & 3.0 & 2 & Betaferon \\
\hline 12 & $\mathrm{~F}$ & 65 & 1.73 & 64.0 & 0.84 & 0.84 & 5 & 7 & 4.0 & 6 & $\mathrm{Nil}$ \\
\hline 13 & $\mathrm{~F}$ & 26 & 1.52 & 60.8 & 0.69 & 0.69 & 0 & 0 & 3.5 & 1 & $\mathrm{Nil}$ \\
\hline 14 & $\mathrm{~F}$ & 23 & 1.66 & 61.6 & 0.81 & 0.81 & 0.5 & 5 & 3.0 & 6 & Betaferon \\
\hline
\end{tabular}

subjects, and, (3) examine the relation between changes in self rated fatigue and gait performance from morning to afternoon in patients with MS.

\section{METHOD \\ Subjects}

A total of 28 subjects were recruited for this study, which was approved by La Trobe University and Kingston Center research and ethics committees. These included 14 patients (table 1) diagnosed with MS by a neurologist, geriatrician, or rehabilitation specialist and 14 control subjects. Each group had eight women and six men. The patients with MS were recruited from the Multiple Sclerosis Society of Victoria and the Movement Disorders Clinic at Kingston Center. They had a range of impairments including spasticity, weakness, incoordination, and postural instability. Patients with MS had mild to moderate levels of disability according to the expanded disability status scale (EDSS), ${ }^{31}$ with a mean EDSS score of 3.8. They were able to walk at least $10 \mathrm{~m}$ without walking devices such as sticks or frames. To be included in the study, patients had to satisfy the following criteria: be able to provide informed consent according to the declaration of Helsinki (1964); be able to walk $14 \mathrm{~m}$ on repeated occasions without assistance; have no coexisting neurological, cardiothoracic, or orthopaedic conditions; and have no severe tremor or visual disturbance that impaired walking ability.

The control subjects were also recruited from a sample of convenience and included students and staff from La Trobe University and Kingston Center. The mean age of control subjects was 38.3 years (range 23-60); their mean height was 1.7 $\mathrm{m}$ (range 1.56-1.87), and their mean weight was $74 \mathrm{~kg}$ (range 52.2-107.8). The subjects and patients were matched for sex, age ( \pm 5 years) and height $( \pm 0.05 \mathrm{~m})$. All took their usual medications on the day of testing.

\section{Apparatus}

A clinical stride analyzer (B and L Engineering, Santa Fe, CA, USA) was used to analyze the temporal and spatial variables of gait. This system enables data to be collected for a subject's gait speed, stride length (distance covered in two steps), cadence (steps/minute), and the percentage of the gait cycle spent in double limb support. Double limb support is when both feet are in contact with the ground, and double limb support values are typically increased when people have postural instability. The system consists of a pair of foot switches, a data logger unit, and a hand held control switch. The foot switches, which were worn as insoles within the subject's shoes, contain four pressure sensors positioned at the heel, big toe, and the first and fifth metatarsals that allowed detection of floor contact at each of these points. Each sensor was sampled every 2 ms with data retained when a change occurred for at least $10 \mathrm{~ms}$ in one or more switches. ${ }^{32}$

\section{Procedure}

Two venues were used for data collection to provide greater convenience of location for those participating in the study. These were the MS Society Camberwell, Australia and the Research Laboratory at Kingston Center, Cheltenham, Australia. The venues were set up to ensure similar testing environments, with a $14 \mathrm{~m}$ linoleum covered walkway used for data collection. This was marked by lines at $0,2,12$, and $14 \mathrm{~m}$. Data were collected over the middle $10 \mathrm{~m}$ to avoid measuring the acceleration and deceleration phases of gait. Before the testing day, subjects were instructed to wear comfortable nonrestrictive clothing and flat comfortable shoes as heel height can influence the duration spent in various subphases of the gait cycle. ${ }^{33}$ Data were also collected for age, time since diagnosis of MS, medications, and perceived fatigue. Perceived fatigue was measured using a subjective rating scale from $0-10$, with 0 being no perceived fatigue and 10 being the worst fatigue the subject had ever experienced. The fatigue scale was validated for patients with MS by Frzovic et al, ${ }^{34}$ who showed that it detects changes in self reported fatigue over a 24 hour period.

Before collecting the gait data, one practice walking trial was conducted to ensure that the subject understood the instructions and all the equipment was operating correctly. The tester (CLC or MEM) provided the following instructions: "(NAME), walk to the end of the walkway at your own comfortable pace, starting when I say "go" and stopping when I say "stop". A second trial was conducted and followed by a 15 minute rest period. The foot switches were not removed between trials. Another two trials were conducted followed by a 5 hour break. For the afternoon, subjects were required to sit for a minimum of 15 minutes before the recommencement of testing. The afternoon procedure replicated the morning one. Testing was postponed if the outside temperature exceeded $32^{\circ} \mathrm{C}$ as heat has been found to adversely affect neuromotor performance and psychological states in people with MS. ${ }^{35}$

There were a few missing data points in the data set. Subject 12 from the group with MS was unable to complete the second trial at each of the four testing times, hence the first trial was used for further analysis. In addition, DS data could not be retained for subjects 15-17 due to malfunction of a pressure sensitive foot switch in a small proportion of trials for these subjects.

To determine whether there were differences in gait performance between the two groups for the morning and afternoon testing sessions, a series of two factor (groups $\times$ time 
Table 2 Mean (SD) change scores, 95\% Cl, $t$ values, and correlation coefficients for repeat measures taken over a 5 hour interval for patients with multiple sclerosis

\begin{tabular}{|c|c|c|c|c|c|c|}
\hline Variable & $\begin{array}{l}\text { Mean change } \\
\text { score }(\bar{D})\end{array}$ & $\begin{array}{l}\text { SD of change } \\
\text { score }\left(S D_{\text {diff }}\right)\end{array}$ & $95 \% \mathrm{Cl}$ & $t$ Value & $\begin{array}{l}\text { Product moment } \\
\text { correlation }(r)\end{array}$ & $\begin{array}{l}\text { Intraclass correlation } \\
\text { coefficient }\left(\operatorname{ICC}_{(2,1)}\right)\end{array}$ \\
\hline Speed $(\mathrm{m} / \mathrm{min})$ & 1.64 (faster) & 4.3 & -6.9 to 10.1 & -1.434 & 0.980 & 0.97 \\
\hline Cadence (steps/min) & 1.32 (higher) & 3.8 & -6.13 to 8.8 & -1.309 & 0.979 & 0.97 \\
\hline Stride length $(\mathrm{m})$ & 0.0141 (longer) & 0.056 & -0.096 to 0.124 & -0.949 & 0.977 & 0.97 \\
\hline Double limb support (\% GC) & 1.25 (greater) & 3.3 & -5.2 to 7.7 & -0.142 & 0.891 & - \\
\hline
\end{tabular}

Table 3 Mean (SD) change scores, $95 \% \mathrm{Cl}, t$ values, and correlation coefficients for repeat measures taken over a 5 hour interval in the afternoon for control subjects

\begin{tabular}{|c|c|c|c|c|c|c|}
\hline Variable & $\begin{array}{l}\text { Mean change } \\
\text { score }(\bar{D})\end{array}$ & $\begin{array}{l}\text { SD of change } \\
\text { score }\left(S D_{\text {diff }}\right)\end{array}$ & $95 \% \mathrm{Cl}$ & $t$ Value & $\begin{array}{l}\text { Product moment } \\
\text { correlation }(r)\end{array}$ & $\begin{array}{l}\text { Intraclass correlation } \\
\text { coefficient }\left(\operatorname{ICC}_{(2,1)}\right)\end{array}$ \\
\hline Speed $(\mathrm{m} / \mathrm{min})$ & 1.20 (faster) & 3.3 & -5.3 to 7.7 & -1.366 & 0.919 & 0.96 \\
\hline Cadence (steps/min) & 1.13 (higher) & 2.4 & -3.6 to 5.8 & -1.793 & 0.936 & 0.92 \\
\hline Stride length $(\mathrm{m})$ & 0.00539 (longer) & 0.046 & -0.085 to 0.096 & -0.435 & 0.941 & 0.99 \\
\hline Double limb support (\% GC) & 0.35 (greater) & 1.6 & -2.8 to 3.5 & -0.722 & 0.871 & - \\
\hline
\end{tabular}

of day) repeated measures analyses of variance (ANOVAs) were used to analyze the speed, stride length, cadence, and double limb support results. This analysis also allowed us to examine consistency of performance in each group over the course of the day. In cases where interaction effects were found on ANOVA, $t$ tests were used to identify whether the interaction was due to differences between groups or across occasions of testing, or both. To compensate for the accumulation of family-wise error by the use of multiple $t$ tests, Bonferroni adjustments were used to adjust the $\alpha$ rates for post hoc analyses. Because the data obtained for the double support phase of the gait cycle showed departures from normality, non-parametric statistics (Kruskal Wallis and Wilcoxon signed ranks $T^{+}$test) were used to analyze the data for these variables.

As well as considering the ANOVA results, we evaluated the consistency of gait in each group by analyzing the mean (SD) for each variable in the morning and the afternoon. Change scores from the morning to the afternoon $(\bar{D})$ and SD of these change scores $\left(\mathrm{SD}_{\text {diff }}\right)$ were also calculated to obtain estimates of systematic and random error respectively. To provide clinicians with estimates from which to judge whether true change in performance had occurred (greater than natural gait variability over a 5 hour period), $95 \%$ confidence intervals (95\% CIs) were calculated around these change scores $(95 \%$ $\left.\mathrm{CI}=\bar{D} \pm \mathrm{Z}_{=0.05} \times \mathrm{SD}_{\text {diff }}\right)$.

\section{RESULTS \\ Differences in gait between patients with MS and controls and consistency of performance}

Tables 2 and 3 show the means (SD) of change scores, 95\% CIs, $t$ values, and correlation coefficients for the MS and control groups. Figure 1 shows the results for speed, stride length, cadence, and double limb support duration for each of the four gait trials in the morning and afternoon. Figure 1 A shows a clear difference in walking speed between the two groups for each measurement trial. Whereas the MS group walked at an average speed of 59 (SD 19.7) $\mathrm{m} / \mathrm{min}$, the average speed was 86 (SD 7.5) $\mathrm{m} / \mathrm{min}$ in the control group. The ANOVA confirmed a statistically significant effect for group $(F$ $(1,25)=20.68, p<0.001)$. Figure $1 \mathrm{~A}$ also shows a slight increase in walking speed in both groups over the course of the eight measurement trials. Although this increase over time was statistically significant $(F(1,25)=7.82, p=0.01)$, the mean difference from the morning to the afternoon was only
$1.2 \mathrm{~m} / \mathrm{min}$ in the control group and $1.6 \mathrm{~m} / \mathrm{min}$ in the MS group. Changes of less than $2 \mathrm{~m} / \mathrm{min}$ are considered clinically non-significant. As table 2 shows, the 95\% CIs around the change scores suggest that patients with MS would need to increase their speed by more than $10.1 \mathrm{~m} / \mathrm{min}$ or reduce it by more than $6.9 \mathrm{~m} / \mathrm{min}$ to show changes greater than the effects of natural variation and measurement error.

For stride length, repeated measures ANOVA showed a statistically significant main effect for group $(F(1,25)=19.062$, $\mathrm{p}<0.001$ ) although there was no effect for trials and no interaction between group and trials. Stride lengths for both groups were consistent over time, with a high degree of repeatability in performance over both the 15 minute interval in the morning and afternoon, and over the 5 hour interval from morning to afternoon (fig $1 \mathrm{~B}$ ). As shown in tables 2 and 3 , the change scores from the morning to the afternoon were small, as were the SDs of these change scores. The mean change was only $0.0141 \mathrm{~m}$ for patients with MS, suggesting only a very small amount of systematic error of measurement. As with the speed results, the $95 \%$ CIs around the change scores for stride length were small. For clinicians to demonstrate significant changes with treatment, patients with MS would need to increase their stride length more than $0.124 \mathrm{~m}$ to show improvement or reduce it by more than 0.096 $\mathrm{m}$ to show deterioration.

The cadence results supported the trend of stability over time. As shown by figure $1 \mathrm{C}$, there was only a very small increase in cadence over the course of the day, with the rate of increase similar in the MS and control groups. This small increase over time was statistically significant $(F(1,25)=6.87$, $\mathrm{p}=0.015)$. The mean change from morning to afternoon was only 1.32 steps/min in the MS group (table 2 ) and 1.13 steps/ min in the control group (table 3 ). There was no significant difference between groups for cadence, and no interaction effect. The $95 \%$ CIs around the change scores were small, with patients needing to increase their cadence more than 8.8 steps/min to show improvement or reduce it by more than 6.1 steps/min to confidently conclude that significant deterioration had occurred with treatment.

The results for the percentage of the gait cycle spent in the double limb support phase, where both feet were in contact with the ground, also remained stable from morning to afternoon (fig l D). There were no significant differences between groups, no differences over time, and no interaction effects for this variable, although the difference between groups approached statistical significance $(F(1,22)=4.25, \mathrm{p}=0.051)$. 

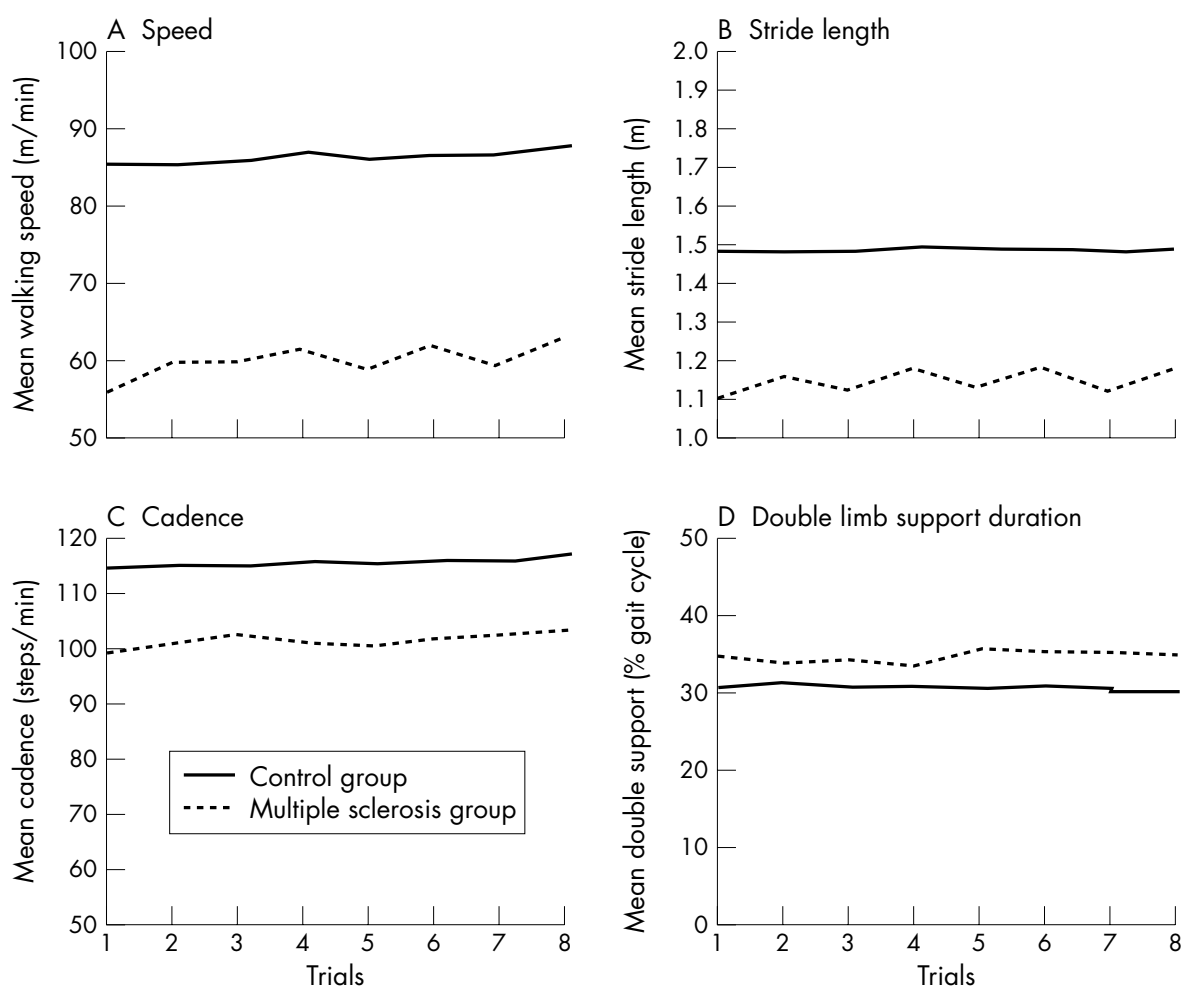

Figure 1 Group mean, speed, stride length, cadence, and double limb support duration for each of the four gait trails in the morning and afternoon.

\section{Relation between self rated fatigue and gait performance}

The mean fatigue ratings for the MS group increased from the morning (mean 2.5 (SD 2.43)) to the afternoon (mean 3.75 (SD 2.75)). This difference was statistically significant $(t$ $(13)=-3.14, p=0.008)$. However, the correlation between change in self rated fatigue from morning to afternoon and change in gait speed from morning to afternoon was poor $(r=0.025, \mathrm{p}=0.993, \mathrm{n}=14)$ and not statistically significant. Likewise there were poor correlations between changes in self rated fatigue and stride length $(r=-0.18, \mathrm{p}=0.537, \mathrm{n}=14)$, cadence $(r=0.153, \mathrm{p}=0.601, \mathrm{n}=14)$, and double limb support duration $(r 0.334, \mathrm{p}=0.243, \mathrm{n}=14)$.

\section{DISCUSSION}

Gait in patients with MS: changes from morning to afternoon

As with previous research, ${ }^{15-20}$ this study showed that patients with MS walked with a slow, short stepped, low cadence gait pattern. The mean values for speed, cadence, and stride length were similar to those reported by Gehlsen et al, whose sample closely resembled the patients in this study. Whereas Benedetti et al, Orsnes et al, and Piperno et al found that the proportion of the gait cycle spent with both feet in contact with the ground was higher in patients with MS than control subjects, the current study failed to identify a statistically significant difference between groups for double limb support duration. It has been argued that increases in double limb support are a compensation for deficits in balance and postural control. ${ }^{36}$ It is possible that the sample selected for this investigation had a smaller proportion of patients with involvement of vestibular, brain stem, spinal, or other CNS regions subserving balance and postural control, compared with previous studies.

There was little change in any of the gait variables in either the MS or control groups from morning to afternoon. Most subjects demonstrated only very small increases in speed, stride length, and cadence. For both groups the mean increase in gait speed was less than $2 \mathrm{~m} / \mathrm{min}$, the mean increase in stride length was less than $0.05 \mathrm{~m}$, and the mean increase in cadence was less than $1.5 \mathrm{steps} / \mathrm{min}$. Changes in double limb support duration were negligible. The small increase in speed, stride length, and cadence over the course of the eight trials is characteristic of practice effects that are often seen in studies of human locomotion. There is evidence showing a tendency for unimpaired people repeating several walking trials in succession to increase their speed. ${ }^{37}$ The slight increases in speed and other variables seen in this study are within the bounds of normal variations in walking documented for unimpaired people. These results are counter to the belief that patients with MS perform more poorly in the afternoon than in the morning.

\section{Relation between changes in fatigue and changes in gait}

This study showed that self rated fatigue significantly increased from the morning to the afternoon whereas the footstep patterns remained the same. These findings are in agreement with those of Krupp et al, who reported no direct relation between neurological disability and perceived fatigue and Schwartz et al, who found no direct relation between self reported fatigue and ambulation. In addition, van der Werf et $a l^{38}$ showed that fatigue in patients with MS was unrelated to cerebral abnormalities measured on MRI and Schubert et al ${ }^{39}$ found that leg fatigue measured by transcranial magnetic stimulation was similar in control subjects and patients with MS. These findings suggest that motor control mechanisms regulating human locomotion are different from those regulating perceived fatigue. Although in the afternoon a person with MS might experience heightened feelings associated with fatigue, such as lethargy, tiredness, lack of energy, and a belief that they are "physically worse", there was no evidence in this study to show that these subjective reports correlated with changes in physical performance. Clinicians should therefore be cautious about patients' self reports relating to 
their changes in motor performance over the course of a day as their feelings associated with fatigue could potentially confound judgements regarding their physical ability.

\section{CONCLUSION}

This study is the first to document the repeatability of gait in patients with MS over a period of 5 hours. Analysis of spatial and temporal variables of the footstep pattern showed that patients with MS had a symmetric, short stepped, slow gait with little variability in performance from morning to afternoon. When evaluating the effects of treatment, clinicians can be relatively confident that large changes over a 5 hour interval are mainly due to the effects of therapy, medication, or factors other than natural fluctuations in walking performance. The finding that self rated fatigue significantly increased from the morning to the afternoon whereas walking patterns remained the same suggests that the mechanisms controlling locomotion are different from those regulating perceived fatigue. These findings may also indicate that clinicians should use objective measures of performance rather than relying solely upon self report to monitor change in people with this debilitating disease.

\section{ACKNOWLEDGEMENTS}

Financial support was granted by the National Multiple Sclerosis Society of Australia Research Advisory Board in the form of a Summer Vacation Scholarship. Dr Owen White and Dr Elizabeth McDonald are thanked for assisting with subject recruitment.

\section{Authors' affiliations}

M E Morris, C Cantwell, K Dodd, School of Physiotherapy, La Trobe University, Bundoora, 3086, Australia

L Vowels, Multiple Sclerosis Association of Victoria, Toorak, Australia

\section{REFERENCES}

1 Compston A. Non-infective, demyelinating, and paraneoplastic diseases of the nervous system. In: Walton J, ed. Brain's diseases of the nervous system. 10th ed. Oxford: Oxford University Press, 1993:366-79.

2 Kidd D, Barkhof F, McConnell R, et al. Cortical lesions in multiple sclerosis. Brain 1999;122:17-26.

3 Lassmann $\mathbf{H}$. The pathology of multiple sclerosis and its evolution. Philos Trans R Soc Lond B Biol Sci 1999;354:1635-40.

4 Poser S, Wikstrom J, Baver HJ. Clinical data and the identification of special forms of multiple sclerosis in 1271 cases studied with a standardized documentation system. J Neurol Sci 1979;40:159-68.

5 Losseff NA, Webb SL, O'Riordan Jl, et al. Spinal cord atrophy and disability in multiple sclerosis: a new reproducible and sensitive method with potential to monitor disease progression. Brain 1996;119:701-8.

6 Oppenheimer DR. The cervical cord in multiple sclerosis. Neuropathol Appl Neurobiol 1978;4:151-62

7 Smith KJ, McDonald WI. The pathophysiology of multiple sclerosis: the mechanisms underlying the production of symptoms and the natural history of the disease. Philos Trans R Soc Lond B Biol Sci 1999;354: 1649-73.

8 Weinshenker BG. The natural history of multiple sclerosis. Neurol Clin 1995;13:119-46.

9 Weinshenker BG, Bass B, Rice GP, et al. The natural history of multiple sclerosis: a geographically based study. I. Clinical course and disability. Brain 1989;112:133-46.

10 Confavreux C, Aimard G, Devic M. Course and prognosis of multiple sclerosis assessed by the computerised data processing of 349 patients. Brain 1980;103:281-300.

11 McDonald WI, Ron MA. Multiple sclerosis: the disease and its manifestations. Philos Trans R Soc Lond B Biol Sci 1999;354:1615-22.
12 Revesz T, Kidd D, Thompson AJ, et al. A comparison of the pathology of primary and secondary progressive multiple sclerosis. Brain 1994; 1 17:759-65.

13 Scheinberg L, Holland N, LaRocca NG, et al. Multiple sclerosis. Earning a living. New York State Journal of Medicine 1980;80:1395-400.

14 Schapiro RT. Multiple sclerosis. A rehabilitation approach to management. New York: Demos, 1991.

15 Benedetti MG, Piperno R, Simoncini L, et al. Gait abnormalities in minimally impaired multiple sclerosis patients. Mult Scler 1999;5:363-8.

16 Gehlsen G, Beekman K, Assmann N, et al. Gait characteristics in multiple sclerosis: progressive changes and effects of exercise on parameters. Arch Phys Med Rehabil 1986;67:536-9.

17 Jones R, Rees DP, Campbell M. Tibialis anterior surface EMG parameters change before force output in multiple sclerosis patients. Clin Rehabil 1994;8:100-6.

18 Orsnes GB, Sorensen PS, Larsen TK, et al. Effect of baclofen on gait in spastic MS patients. Acta Neurol Scand 2000;101:244-8.

19 Piperno R, Reali A, Puletti C, et al. Le alterazioni del cammino nella sclerosi multipla. Analisi dei parametri tempo-distanza (Changes in the gait of multiple sclerosis. Analysis of time-distance parameters). Europa Medicophysica 1991;27:69-78

20 Rodgers MM, Mulcare JA, King DL, et al. Gait characteristics of individuals with multiple sclerosis before and after a 6-month aerobic training program. J Rehabil Res Dev 1999;36:183-8

21 Krupp LB, Alvarez LA, LaRocca NG, et al. Fatigue in multiple sclerosis. Arch Neurol 1988:45:435-7.

22 Provinciali L, Ceravolo MG, Bartolini M, et al. A multidimensional assessment of multiple sclerosis: relationships between disability domains. Acta Neurol Scand 1999;100:156-62.

23 Schwartz CE, Coulthard-Morris L, Zeng Q. Psychosocial correlates of fatigue in multiple sclerosis. Arch Phys Med Rehabil 1996;77:165-70.

24 Colosimo C, Millefiorino E, Grasso M, et al. Fatigue in multiple sclerosis is associated with specific clinical features. Acta Neurol Scand 1995;92:353-5

25 Cobble $\boldsymbol{M}$. The rehabilitative management of fatigue associated with multiple sclerosis. Arch Neurol 1992;46:676-80.

26 Detels $\mathbf{R}$, Clark VA, Valdiviezo NL, et al. Factors associated with a rapid course of multiple sclerosis. Arch Neurol 1982;39:337-41.

27 Laver K, Firnhaber W. Epidemiological investigations into multiple sclerosis in Southern Hesse. V. Course and prognosis. Acta Neurol Scand 1987;76:12-7

28 Holden MK, Gill KM, Magliozzi MR, et al. Clinical gait assessment in the neurologically impaired. Reliability and meaningfulness. Phys Ther 1984;64:35-40

29 Olgiati R, Burgunder JM, Mumenthaler M. Increased energy cost of walking in multiple sclerosis: effect of spasticity, ataxia, and weakness. Arch Phys Med Rehabil 1988;69:846-9.

30 Vaney C, Blaurock H, Gattlen B, et al. Assessing mobility in multiple sclerosis using the Rivermead Mobility Index and gait speed. Clin Rehabil 1996;10:216-26.

31 Kurtzke JF. Rating neurologic impairment in multiple sclerosis: an expanded disability status scale (EDSS). Neurology 1983;33:1444-52.

32 Morris ME, lansek R, Matyas TA, et al. The pathogenesis of gait hypokinesia in Parkinson's disease. Brain 1994;117:1169-81.

33 Eisenhardt JR, Cook D, Pregler I, et al. Changes in temporal gait characteristics and pressure distribution for bare fee versus various heel heights. Gait Posture 1996;4:280-6.

34 Frzovic D, Morris ME, Vowels L. Clinical tests of standing balance: performance of persons with multiple sclerosis. Arch Phys Med Rehabil 2000;81:215-21.

35 Syndulko K, Ke D, Ellison GW, et al. Comparative evaluations of neuroperformance and clinical outcome assessments in chronic progressive multiple sclerosis: I. Reliability, validity and sensitivity to disease progression. Multiple Sclerosis Study Group. Mult Scler 1996;2:142-56.

36 Gabell A, Nayak USL. The effect of age on variability in gait. J Gerontol 1984;39:662-6

37 Guyatt GH, Pugsley SO, Sullivan M, et al. Effect of encouragement on walking test performance. Thorax 1984;39:818-22.

38 van der Werf SP, Jongen PJH, Lycklama a Nijeholt GJ, et al. Fatigue in multiple sclerosis: interrelations between fatigue complaints, cerebral MR abnormalities, and neurological disability. J Neurol Sci 1998; 160:164-70.

39 Schubert M, Wohlfarth K, Rollnik JD, et al. Walking and fatigue in multiple sclerosis: the role of the corticospinal system. Muscle Nerve 1998;21:1068-70. 